\title{
Assessment of Risky Lifestyle Behaviour Among Undergraduate Students of a Tertiary Institution in Delta State, South-South, Nigeria
}

\author{
Adje Ufuoma David“, Igbinedion Precious, Achi Chukwubuikem James
}

Department of Clinical Pharmacy and Pharmacy Administration, Delta State University, Abraka, Nigeria

Email address:

a_udave77@yahoo.com (A. U. David),duadje@delsu.edu.ng (A. U. David)

${ }^{*}$ Corresponding author

\section{To cite this article:}

Adje Ufuoma David, Igbinedion Precious, Achi Chukwubuikem James. Assessment of Risky Lifestyle Behaviour Among Undergraduate Students of a Tertiary Institution in Delta State, South-South, Nigeria. Central African Journal of Public Health.

Vol. 6, No. 4, 2020, pp. 232-236. doi: 10.11648/j.cajph.20200604.18

Received: July 11, 2020; Accepted: July 27, 2020; Published: August 18, 2020

\begin{abstract}
Young persons are vulnerable to risky health behaviors which can predispose them to serious morbidities later in life. The objectives of this study were to identify risky lifestyle habits among college students and explore the relationship between unhealthy habits and self- reported academic performance. An adapted behavioral risk factor surveillance system (BRFSS) questionnaire was administered to 400 college students by systematic random sampling, Anonymously filled questionnaires were deposited at agreed safe locations after completion and retrieved thereafter. Data was analyzed using SPSS for windows version 21. Chi Square Test which was used to explore possible association between demographic variables and responses. Level of significance was set at 0.05 . The median age of respondents was 22 years (range 17-30). Prevalence of prescription drug (codeine) abuse was $17.3 \%$ while use of tobacco, alcohol and hard drugs were $14 \%$., $56.2 \%$ and $9.3 \%$ respectively. More than half of the students were sexually active with more males $79(35 \%)$ reporting multiple sexual partners. More than half, $163(68.5 \%)$ of those who had ever engaged in sexual intercourse claimed that they always or sometimes use some form of protection. More than three quarters ate breakfast regularly. More males 207 (91.6\%) than females $339(84.8 \%)$ claimed to eat fruits and vegetables regularly. Majority, 339 (84.8\%) admitted eating nodules more than five times a week. The association between alcohol usage and self -reported academic performance was statistically significant but appears not to be negative. However, TV viewing for more than 2 hours a day was significantly associated with poor academic performance, Chi Square 22.940 , df, $12, \mathrm{P}=0.028$. Conclusively, risky lifestyle habits among undergraduate students included smoking, alcohol usage, use of hard drugs and unprotected sexual intercourse. Poor habits that reduce sleep quality could negatively affect students' academic performance.
\end{abstract}

Keywords: Adolescent, Health Risk Behaviors, College Students, Nigeria

\section{Introduction}

Globally young people constitute a significant proportion of the population. Nearly 1 in 5 persons living in the Middle East and Africa are between the ages of 15 to 24 years [1-2]. In Nigeria, youths aged $10-24$ years' account for $32 \%$ of the total population [3]. Generally, young persons are vulnerable to potentially harmful activities because of a high propensity to be involved in risky health behaviors [4]. Such behaviors include use of tobacco and other illicit psychoactive substances, excessive use of alcohol, poor dietary pattern, physical inactivity, lack of sufficient sleep, and unprotected sexual activity [5-7]. The World health organization states that $60 \%$ of a person's quality of health depends on behavior and lifestyle [8]. Therefore, unhealthy lifestyles could predispose youths to chronic diseases in adulthood [9]. A significant proportion of youths 15-19 years are enrolled in colleges or tertiary institutions. Therefore, this is an ideal setting to carry out interventions to prevent and manage risky behaviors in adolescents. Identifying risky lifestyle and determining prevalence of risk factors in adolescents is critical to developing risk reduction strategies [10]. The 
objectives of this study were to identify risky lifestyle habits among college students, determine the proportion of students that smoke cigarettes, take alcohol, engage in substance abuse and unprotected intercourse, determine proportion of students that are physically inactive, have poor dietary and sleep habits and to explore the relationship between unhealthy habits and self- reported academic performance.

\section{Methods}

\subsection{Setting}

The study was conducted in Delta State University, Abraka. Delta state, Nigeria. Delta State is multi-tribal and ethnically diverse state with numerous language groups, comprising of Urhobo, Isoko, Igbo, Ijaws and Itsekiri. Abraka is a town in Ethiope East local government area of Delta State. The town has a general hospital and a busy health center. A number of private health facilities and the University health center provide health care services for the populace. Residents are mainly civil servants and subsistent farmers and fishermen. Delta State University, Abraka (DELSU) is situated in the hearts of Abraka which makes the students the predominant population for most parts of the year.

\subsection{Study Design}

This was a cross sectional qualitative study design that assessed risky lifestyle behaviour among 450 undergraduate students.

\subsection{Study Population}

The population consisted of undergraduates of Delta State University, Abraka.

\subsection{Sample Size/Sampling Technique}

The total number of students enrolled in the University was 30000.

Applying Yamane formula [11-12].

$$
\mathrm{N}=\mathrm{N} / 1+\mathrm{N}(\mathrm{e})^{2}
$$

Where

$\mathrm{N}=$ the population size

$\mathrm{e}=$ the level of precision $(0.05)$

$\mathrm{N}=30000 / 1+30000(0.05)^{2}=400$

This was increased to 450 in order to allow for attrition and incomplete data.

Pre tested self- completion questionnaires were distributed to students who showed a willingness to participate by signing a written informed consent form which contained a clear explanation of the purpose of the study and what was involved. The questionnaire was administered by systematic random sampling to 5 undergraduate students in every $7^{\text {th }}$ room in the halls of residence until the sample size was obtained. Respondents were assured of utmost confidentiality due to sensitive nature of the questions. Anonymously filled questionnaires were deposited at agreed safe locations after completion and retrieved thereafter.

\subsection{Research Instrument}

The behavioral risk factor surveillance system questionnaire, BRFSS) was adapted for the study [13]. This validated questionnaire is a telephone survey administered to adults above 18 years in order to determine health trends and measure progress of prevention initiatives. Minor adjustments were made to the questionnaire to suit the study population. The resulting questionnaire was a 50 item questionnaire was consisting of two sections. The first section dealt with socio demographic data of respondents while the second section assessed risky lifestyle behaviors including current sexual habit, use of alcohol and psychotropic substances, vegetable and fruit consumption, hours of sleep daily and self -reported academic performance.

\subsection{Data Analysis}

Data was analyzed using SPSS for windows version 21 [14]. Questionnaires were coded and checked for errors. Categorical data were expressed as frequencies and proportion while means and standard deviation were computed for continuous variables. Chi Square test which was used to explore possible association between demographic variables and responses. Level of significance was set at 0.05 .

\subsection{Ethical Approval}

Ethical approval was obtained from the Health Research Ethics committee, Delta State University teaching hospital, Oghara, Delta state.

\section{Results}

Four hundred usable questionnaires were retrieved out of the 450 administered giving a response rate of $89 \%$. There were more males 226 (56.5\%) than females 174 (46.5\%). The age range of respondents was from 17 to 30 years with a median age of 22 years. Only $56(14 \%)$ were smokers but more than half $225(56.2 \%)$ consumed alcohol. Prevalence of prescription drug (Codeine) abuse was $17.3 \%$, table 1 .

Table 1. Socio demographic characteristics and prevalence of risky behavior.

\begin{tabular}{llll}
\hline \multirow{2}{*}{ Variable } & No $(\%)$ & \\
\cline { 2 - 4 } & Male & Female & Total \\
\hline Gender & $226(56.5)$ & $174(43.5)$ & $400(100)$ \\
$17-20$ & & & \\
$21-24$ & $57(25.2)$ & $74(42.5)$ & $131(32.75)$ \\
25 and above & $110(48.7)$ & $94(54.0)$ & $204(51.0)$ \\
Behaviour & $56(26.1)$ & $6(3.4)$ & $65(16.3)$ \\
Smoking & & & \\
Alcohol consumption & $142(62.8)$ & $85(48.9)$ & $225(56.3)$ \\
Indian Hemp & $29(12.8)$ & $8(4.6)$ & $37(9.3)$ \\
Glue Sniffing & $53(23.5)$ & $10(5.7)$ & $63(15.8)$ \\
Codeine & $56(24.8)$ & $10(5.7)$ & $63(15.8)$ \\
\hline
\end{tabular}

The most predominant reason for smoking among males 
was to calm down $(5.3 \%)$ while for females, it was curiosity (4\%). Most females took alcohol to calm down (17.8\%) while males consumed alcohol for fun $(17.3 \%)$, table 2 .

Table 2. Reasons for smoking and alcohol; consumption.

\begin{tabular}{lllll}
\hline \multirow{3}{*}{ Variable } & \multicolumn{3}{l}{ No $(\%)$} & \multicolumn{2}{l}{ Alcohol consumption } \\
\cline { 2 - 5 } & Smoking & Memale & Male & Female \\
\cline { 2 - 5 } & Male & N=174 & N=226 & N=174 \\
\cline { 2 - 5 } & $\mathbf{N}=\mathbf{2 2 6}$ & $\mathbf{N}(4.0)$ & $24(10.6)$ & $11(6.3)$ \\
\hline Habit & $14(6.2)$ & $16(9.2)$ & $24(10.6)$ & $39(22.4)$ \\
Curiosity & $19(8.4)$ & $21(12.1)$ & $64(28.3)$ & $67(38.5)$ \\
Calm down & $21(9.3)$ & $5(2.9)$ & $35(15.5)$ & $27(15.5)$ \\
Please friends & $12(5.3)$ & $0(0.0)$ & $66(29.2)$ & $33(19.0)$ \\
For Fun & $18(8.0)$ & $0(0.0)$ & $4(1.8)$ & $0(0.0)$ \\
Get High & $2(0.9)$ & $0(0.0)$ & $2(0.9)$ & $2(1.1)$ \\
Illness & $0(0.0)$ & $0(0.0)$. & $2(0.9)$ & $0(0.0$ \\
Think well & $0(0.0)$ & $0(0.0)$ & $10(4.4)$ & $0(0.0)$ \\
Satisfaction & $14(6.2)$ & &
\end{tabular}

\subsection{Sexual Behavior}

More males 79 (35\%) reported having multiple sexual partners than females $38(21.8 \%)$. The proportion of sexually active males was $93(41.2 \%)$ compared to females 59 (33.9\%). More than half, $163(68.5 \%)$ of those who had ever engaged in sexual intercourse claimed that they always or sometimes use some form of protection, Table 3.

Table 3. Sexual behavior of undergraduate students.

\begin{tabular}{llll}
\hline \multirow{2}{*}{ Variable } & \multicolumn{2}{l}{$\mathbf{N}(\mathbf{\%})$} & \\
\cline { 2 - 4 } & $\mathbf{M a l e}$ & Female & Total \\
\cline { 2 - 4 } & $\mathbf{N = 2 2 6}$ & $\mathbf{N}=\mathbf{1 7 4}$ & $\mathbf{N = 4 0 0}$ \\
\hline Sexual behaviour & & & \\
Ever engaged in sex & $147(65)$ & $87(50)$ & $238(59.5)$ \\
Sexually active & $93(41.2)$ & $59(33.9)$ & $157(39.3)$ \\
Multiple partners & $79(35)$ & $38(21.8)$ & $117(29.3)$ \\
Use Protection & & & \\
Always/Sometime & $102(45.1)$ & $61(35.1)$ & $163(40.8)$ \\
Rarely/Never & $46(20.4)$ & $46(26.4)$ & $92(23 \%)$ \\
\hline
\end{tabular}

\subsection{Physical Activity and Eating Habit}

More than half $242(60.5 \%)$ students claimed to be physically active while $65(17 \%)$ perceived themselves to be overweight or obese. More than three quarters ate breakfast regularly. More males 207 (91.6\%) than females 339 (84.8\%) claimed to eat fruits and vegetables regularly. Majority, 339 (84.8\%) admitted eating nodules more than five times a week while $325(81.5 \%)$ ate junk foods most days of the week. More than three quarters $62(27.4 \%)$ males and nearly half of females $74(42.5 \%)$ deemed their academic performance to be good, Table 4.

Table 4. Dietary, sleep habits and Self-reported academic performance of respondents.

\begin{tabular}{|c|c|c|c|}
\hline \multirow{2}{*}{ Variable } & \multicolumn{3}{|l|}{$\mathbf{N}(\%)$} \\
\hline & Male & Female & Total \\
\hline \multicolumn{4}{|l|}{ Dietary pattern } \\
\hline Regular breakfast & $175(77.4)$ & $135(77.6)$ & $310(77.5)$ \\
\hline Fatty foods $>5$ times a week & $198(87.6)$ & $127(73.0)$ & $325(81.3)$ \\
\hline Soft drinks $>5$ times a week & $207(91.6)$ & $145(83.3)$ & $352(88.0)$ \\
\hline Fruits and vegetables $>5$ times a week & $207(91.6)$ & $142(81.6)$ & $349(87.3)$ \\
\hline Nodules $>5$ times a week & $202(89.3)$ & $137(78.7)$ & $339(84.8)$ \\
\hline \multicolumn{4}{|l|}{ Sleeping habits } \\
\hline Good & $109(48.2)$ & $120(69.0)$ & $229(57.3)$ \\
\hline Average & $86(38.1)$ & $48(27.6)$ & $134(33.5)$ \\
\hline Poor & $31(13.7)$ & $6(3.4)$ & $37(9.3)$ \\
\hline \multicolumn{4}{|l|}{ Sleep hours } \\
\hline Sufficient & $138(61.1)$ & $140(80.5)$ & $278(69.5)$ \\
\hline Insufficient & $88(38.9)$ & $34(19.5)$ & $122(30.5)$ \\
\hline \multicolumn{4}{|l|}{ TV Viewing } \\
\hline 2 hrs. daily or more daily & $39(17.3)$ & $25(14.4)$ & $64(16.0)$ \\
\hline Less than 2 hrs. daily & $116(51.3)$ & $96(55.2)$ & $212(53.0)$ \\
\hline \multicolumn{4}{|l|}{ Self -reported academic performance } \\
\hline Excellent & $62(27.4)$ & $74(42.5)$ & $136(34)$ \\
\hline Good & $129(57.1)$ & $84(48.3)$ & $213(53.3)$ \\
\hline Fair & $33(14.6)$ & $15(8.6)$ & $48(12.0)$ \\
\hline Poor & $2(0.9)$ & $11(0.6)$ & $3(0.8)$ \\
\hline
\end{tabular}

There were statistically significant associations between self- reported academic performance and lifestyle habits, Table 5 .

Table 5. Association between alcohol usage, TV viewing and self-reported academic performance.

\begin{tabular}{|c|c|c|c|c|c|c|c|c|}
\hline \multirow{2}{*}{ Variables } & & \multicolumn{7}{|c|}{ Academic performance N (\%) } \\
\hline & & Excellent & Good & Fair & Poor & $\mathbf{X}^{2}$ & df & P value \\
\hline \multirow[t]{2}{*}{ Alcohol Usage } & Yes & $64(28.4)$ & $124(55.1)$ & $35(15.5)$ & $2(0.89)$ & 10.553 & 3 & 0.014 \\
\hline & No & $72(41.1)$ & $89(50.9)$ & $13(7.4)$ & $1(0.6)$ & & & \\
\hline \multicolumn{9}{|l|}{ TV Viewing } \\
\hline & Less than 2 hrs. & $123(36.60$ & $167(49.7)$ & $0(0)$ & $3(0.9)$ & & & \\
\hline & $2 \mathrm{hrs}$ or more & $13(20)$ & $46(71.9)$ & $43(67.2)$ & $5(7.8)$ & 22.940 & 12 & 0.028 \\
\hline
\end{tabular}




\section{Discussion}

The study assessed prevalence of risky lifestyle behaviors among undergraduate students. Prevalence of tobacco use was $14 \%$. This is relatively low compared to prevalence rate obtained among undergraduate students in Ilorin, Nigeria (57\%) [15], Port Harcourt, Nigeria, (36.1\%) [16], Italy (24\%) [17], and Lebanon, 20\% [18]. Prevalence of alcohol use in this study was similar to results obtained from a South African study which reported $57 \%$ and $5 \%$ for males and females respectively [19]. This was even higher than rates obtained from Lebanon, 31\% males and 8.6\% females [18]. About $10 \%$ of respondents admitted using Indian hemp. This finding is consistent with a Nigerian study which showed a significant increase in the use of cannabis and other stimulants among youths in the Nigerian society [20]. Studies from other parts of the world show high rates of drug use among undergraduate students. For instance, $40 \%$ of students in Italy admitted smoking joint at least once a week. [17]. More than half of the students were sexually active. Similar rates were obtained in a study conducted in South Africa [21].

Less than half of the students in this study use some form of protection compared to $89.3 \%$ of sexually active students in South Africa who use protection regularly [21]. Use of condom among youths have been consistently low in many developing countries [2, 22-23]. The South African exception may be due to the relatively high prevalence of HIV in the South African population,[24] our findings may indicate a need for educational programs aimed at increasing the use of condoms and other protective measures among youths in the Nigerian society.

The association between alcohol usage and self -reported academic performance was statistically significant but appears not to be negative. However, TV viewing for more than 2 hours a day was significantly associated with poor academic performance. Tobacco use, poor dietary habits, physical inactivity, substance use, sleep problems, and depression symptoms have been associated with poor selfreported academic performance [25-26]. Focusing on some of these factors could be helpful in tackling underperformance among university students.

A major limitation of the study was that the key outcome measures were self- reported. Also direct assessment of weight, academic performance and other variables would have increased the reliability and generalization of the study findings.

\section{Conclusion}

Risky lifestyle habits among undergraduate students included smoking, alcohol usage, use of hard drugs and unprotected sexual intercourse. Poor habits that reduce sleep quality can negatively affect students' academic performance. The findings in this study could be deployed by policy makers and governments in designing lifestyle and behavioral risk reduction strategies to ensure optimal adolescent health in Africa and other developing countries of the world.

\section{Acknowledgements}

Our sincere thanks to the University management and hostel potters for their support and cooperation during this study.

\section{References}

[1] Isiugo-Abanihe, UC. Adolescents' Sexuality and Sexual Behavior: What we know and do not know. In: FE Okonofua and R. Imade (eds.) Identifying Priorities for Research and Documentation on Adolescent Sexual Reproductive Health in Nigeria, 2011: 27-37. Benin City: WHARC.

[2] Isiugo-Abanihe U C, Olajide R, Nwokocha E, Fayehun F, Rasheed Okunola R, Akingbade R Adolescent Sexuality and Life Skills Education in Nigeria: To What Extent Have Outof-School Adolescents Been Reached? African Journal of Reproductive Health March 2015; 19 (1): 101.

[3] National Population Commission (NPC) [Nigeria] and ORC Macro. Nigeria Demographic and Health Survey 2009. 2008. Calverton, Maryland.

[4] Pringle J, Doi L, Jindal-Snape D, Jepson R and McAteer J. Adolescents and health-related behavior using a framework to develop interventions to support positive behaviours. Pilot and Feasibility Studies 2018, 4: 69 https://doi.org/10.1186/s40814018-0259-7.

[5] Okafor I, Obi S N Sexual risk behaviour among undergraduate students in Enugu, Nigeria. Journal of Obstetrics and Gynaecology, 2005, 25: 6, 592-595, DOI: $10.1080 / 01443610500239511$.

[6] Ajaegbu O Premarital Sex, HIV and Use of Condom among Youths in Nigeria. Arts Social Sci. J. 2015, 6: 146. doi: 10.4172/2151-6200.1000146.

[7] Atlam DH, Aldemir E, Altintoprak AE. Prevalence of risky behaviours and relationship of risky behaviours with substance use among university students. The Journal of Psychiatry and Neurological Sciences 2017; 4 (30): 287-298. https://doi.org/10.5350/DAJPN2017300402.

[8] WHO. Regional Office for Europe Healthy living: what is a healthy lifestyle? Copenhagen: WHO regional Office for Europe. $1999 . \quad$ Available at http://www.who.int/iris/handle/10665/108180. Accessed3/4/18.

[9] Kipping R, Campbell RM, MacArthur GJ, Gunnell D J, Hickman M Multiple risk behaviour in adolescence. Journal of Public Health, 2012, Vol. 34, No. S1, pp. i1-i2 | doi: 10.1093/pubmed/fdr122 EDITORIAL.

[10] Kohli A, Remy MM, Binkurhorhwa AK, Mitima CM, Mirindi AB, Mwinja NB, Banyewesize JH, Ntakwinja GM, Perrin NA, Glass N. Preventing risky behaviours among young adolescents in eastern Democratic Republic of Congo: A qualitative study. Glob Public Health. 2018 Sep; 13 (9): 12411253. 
[11] Taro Y. Statistics: An Introductory Analysis. 2nd Ed. New York, Harper and Row. 1967.

[12] Kasinlevicius V, Sapoka V, Filipaviciute R Sample size calculation in epidemiological studies. Gerontologija 2006; 7: 225-231.

[13] Centers for Disease Control and Prevention (CDC). Behavioural Risk Factor Surveillance System Survey Questionnaire. Atlanta, Georgia: U.S. Department of Health and Human Services, Centers for Disease Control and Prevention-2011. Available http://www.cdc.gov/brfss/questionnaires/pdfques/2011brfss.pdf.

[14] IBM Corp. Released 2012. IBM SPSS Statistics for windows, Version 21.0. Armonk, NY: IBM Corp.

[15] Fawibe A E, Shittu A O Prevalence and characteristics of cigarette smokers among undergraduate of the University of Ilorin, Nigeria, Nig J Med, 2011: 14: 201-205.

[16] Imaledo JA, Peter-Kio OB, Asuquo EO. Pattern of risky sexual behaviour and associated factors among undergraduate students of the University of Port Harcourt, Rivers State, Nigeria. The Pan African Medical Journal. 2012; 12: 97.

[17] Poscia A, Parente P, Frisicale EM, Teleman AA, de Waure C, Di Pietro ML, Di Pietro ML. Risky behaviours among university students in Italy. Ann Ist Super Sanita. 2015; 51 (2): $111-5$.

[18] Salameh, P, Jomaa, L, Issa, C. Farhat, G Zeghondi, H, Gerges, N. Sabbagh, M. T. Chaaya, V, Barbour, B, Waked, M., Salamé, J, Saadallah-Zeidan N \& Baldi I. Assessment of health risk behaviours among university students: a cross-sectional study in Lebanon, International Journal of Adolescence and Youth, 2014, 19: 2, 203-216.
[19] Peltzer K, Phaswana N Substance abuse among South African university students: a quantitative and qualitative study. Urban Health and Development bulletin; 1999; Mar, 2 (1): 63-68.

[20] Adelekan M L, Ndom R J, Trends in prevalence and pattern of substance use among secondary school pupils in Ilorin. West Afr. J Med 1997; 16: 157-164.

[21] Hoque ME Reported risky sexual practices amongst female undergraduate students in KwaZulu-Natal, South Africa. Afr J Prim Health Care Fam. Med. 2011; 3 (1): a281, 6 pages.

[22] Imaledo $\mathrm{J} \mathrm{A}$, Peter-Kio O B and Arulogun O S Risky behaviours of undergraduate students of Ignatius Ajuru University of Education, Port Harcourt, Rivers State, Nigeria during Christmas period Educational Research 2013, 4 (7): 561-568.

[23] Menon J A, Mwaba S O C, Kusanthan T and Lwatula C Risky Sexual Behaviour among University Students. International STD Research \& Reviews 4 (1): 1-7, 2016 Article no. ISRR. 25462.

[24] Mabaso, M., Makola, L., Naidoo, I. et al. HIV prevalence in South Africa through gender and racial lenses: results from the 2012 population-based national household survey. Int J Equity Health 18, 167 2019. https://doi.org/10.1186/s12939-019-1055-6.

[25] Bourdeaudhuij, I., \& Deforche, B. Weight, Sociodemographics, and health behaviour related correlates of academic performance in first year university students. Nutrition Journal, 2013, 12, 162. doi: 10.1186/1475-2891-12162.

[26] Peltzer, K, Pengpid S Health Behaviour and Self-reported Academic Performance among University Students: An International Study Mediterranean Journal of Social Sciences Vol 5 No 27 December 2014 Doi: 10.5901/mjss. 2014. V5n27p998. 